\title{
CRISE, MUDANÇA E INTERMEDIÁRIO: O PAPEL DO PROFESSOR DE CIÊNCIAS NA CONSTITUIÇÃO DAS RELAÇÕES INTERSUBJETIVAS EM UM GRUPO DE PROFESSORES
}

\author{
Crisis, Change and the Intermediary: \\ The Role of the Science Teacher in the Establishment of \\ Intersubjective Relationships in a Group of Teachers \\ Juarez Melgaço Valadares(1) \\ Alberto Villani (2)
}

\begin{abstract}
RESUMO: A elaboração e sustentação de projetos coletivos supõem a inscrição do sujeito em um contrato normativo do qual ele é um elo e ao qual se submete. Tal contrato é articulador de sua vida psíquica no grupo e na instituição, e garante a continuidade dos projetos educativos. Nesse trabalho, analisaremos o papel de uma professora de ciências no desenvolvimento das relações intersubjetivas de um grupo de professores de uma escola. Focalizaremos um deslocamento dos vínculos estabelecidos em função de uma elaboração simbólica propositiva da professora e, a seguir, a sua saída do grupo. Para responder à questão formulada faremos uma triangulação entre dados colhidos de entrevistas, relatos e documentos, e em conceitos da teoria psicanalítica de René Kaës. Mostraremos a importância do conceito de intermediário como analisador de grande heurística, possibilitando encontrar marcas que permitem ao sujeito reconhecer-se e ser reconhecido como sujeito do grupo.
\end{abstract}

Palavras-chave: comunidade de professores, projeto pedagógico, psicanálise e educação

ABSTRACT: The elaboration of and support for collective projects implies in subject's agreement with a normative contract. This contract articulates one's psychic life in the group and in the institution, as well as guarantees the continuity of educational projects. In this work, we analyze the role of a science teacher in the development of intersubjective relationships of a group of teachers from the same school. We will focus on the shift of bonds that were established through propositive symbolic elaboration from that teacher, who ended up leaving the group. Data from diverse sources was triangulated and examined through the lens of concepts from René Kaës' psychoanalytic theory. We show the importance of the concept "intermediary" for analysis, permitting one to identify the signs that make it possible for the subject to recognize him/herself and to be recognized as a member of the group.

Key-words: teacher community, psychoanalyze and education, pedagogic project

(1) Programa de Pós-Graduação da Faculdade de Educação - USP, juares@pbh.gov.br

(2) Instituto de Física - USP, com auxílio parcial do CNPq, avillani@if.usp.br 


\section{INTRODUÇÃO}

Em trabalhos anteriores analisamos os processos de subjetivações decorrentes das relações instituintes de um grupo de professores na construção de projetos interdisciplinares (Valadares \& Villani, 2001; Valadares \& Villani, 2002). Nesses trabalhos, respaldados pelos conceitos de intermediário e aparelho psíquico grupal da teoria psicanalítica do francês René Kaës (1991; 1997), mostramos a importância do conceito de crise e mudança no desenvolvimento das relações grupais, e a construção de intermediários como alimentador do dinamismo e sustentação do grupo. Em um contexto complexo e imprevisível como o cotidiano escolar, procuramos localizar e identificar os elementos mediadores que o configuram, sustentam e fornecem apoio às mudanças.

A noção de crise implica acontecimentos produtores de uma mudança qualitativa de uma situação pré-existente. É considerada uma experiência de ruptura no transcurso das experiências vividas, uma quebra ou modificação imprevista de laços intersubjetivos, e refletem nas atividades didáticas. A noção de crise vincula-se à desorganização, angústia, incerteza, e possíveis ameaças ao projeto educativo. Os intermediários, nesse sentido, funcionam como conector nesses momentos, podendo tanto desencadear movimentos de criação, transformando o grupo, quanto situações de paralisia - quando ocorre uma falha na sua construção -, bloqueando o grupo na consecução de seus objetivos.

Nesse trabalho analisaremos o papel da professora de ciências no desenvolvimento das relações intersubjetivas de um grupo de professores. Esse coletivo, em 1996, encontravase disposto a dar continuidade aos projetos interdisciplinares iniciados no ano anterior. Diferentemente do primeiro projeto, a estruturação curricular seria elaborada em parceria com os alunos, orientada pela pedagogia de projetos. A escola, a partir de questões problematizadoras, dividiu os alunos em vários agrupamentos, ora com base na turma de referência, ora diversificando os alunos das várias classes. Definiu-se, dessa forma, tanto os conteúdos como as estratégias de trabalho coletivo. Inicialmente, a professora de ciências aparentava certo descompromisso com o projeto: achava que os alunos não estavam correspondendo e mostrava-se agressiva com os colegas e com os próprios alunos. Foi chamada para uma reunião com a coordenação da escola, pois se acreditava que suas atitudes comprometiam o grupo. Por outro lado, em uma reunião de planejamento do trabalho, propôs de maneira criativa a leitura de um livro sobre sexualidade com os alunos, o que foi aceito pelo grupo; porém, no final do ano, a coordenação pedagógica solicitou a não-permanência da professora no projeto. Após sua saída, outros vínculos foram configurados, e o grupo adquiriu maior autonomia. Temos, nesse momento, um impasse: uma professora que contribui de maneira valiosa e não consegue ser reconhecida como membro do grupo. Indaga-se: Que exigências são impostas ao professor? Qual o 
significado da pertinência de um membro a um grupo?

Nas conclusões, mostraremos a importância do conceito de intermediário como um analisador de grande heurística. O conceito clareia os núcleos dramáticos nos momentos de mudança - que une cada sujeito ao outro e cada um consigo mesmo e o grupo constituindo, conforme nos escreve Kaës (1997), os apoios que justificam a pertinência do sujeito ao grupo. A intenção é localizar, por um lado, as exigências do trabalho psíquico impostas pelo grupo a seus sujeitos, e, por outro, o submetimento ao grupo como exigência do próprio sujeito. Possibilita encontrar, sobremaneira, as marcas identificatórias que o fazem reconhecer-se e ser reconhecido como sujeito do/no grupo.

\section{REFERENCIAL TEÓRICO}

$\mathrm{Na}$ organização das ações na escola os professores produzem relações entre si e com os objetos situadas além do envolvimento cognitivo com as tarefas. Discutiremos tais relações, principalmente as que ocorrem na passagem das práticas individuais para as práticas coletivas, e na sustentação dessas, localizando as mediações dos sujeitos entre si e destes com os objetos (grupo, projetos, instituição), articuladoras desses diferentes componentes. Nosso referencial teórico será baseado em conceitos propostos pelo psicanalista francês René Kaës (1997) que, por considerar a base intersubjetiva da vida psíquica do sujeito singular, persegue os efeitos e agenciamentos que o agrupamento produz nesse sujeito, e as condições que propiciam a sua subjetivação. A constituição da realidade psíquica do sujeito será pensada a partir do lugar que ocupa na estrutura psíquica do grupo ou instituição. Deparamos, no referencial proposto, com um indicador de uma realidade psíquica específica do grupo: o Aparelho Psíquico Grupal (APG).

O grupo e a instituição, devido a heterogeneidade psíquica de seus membros e dos diversos âmbitos (psíquicos, sociais, jurídicos) que o atravessam, tendem a homogeneizar e unificar seus membros em um mesmo ideal ou matriz identificadora, configurando um modo de funcionamento do APG que denominamos isomórfico. Porém, deixa também espaços por onde podem surgir os processos de diferenciação entre os sujeitos, cuja modalidade de funcionamento do APG é denominado homomórfico. A tensão dialética entre os dois pólos produz movimentos de continuidade e ruptura entre os sujeitos, grupos e instituição. Uma das formas de perceber o desenvolvimento da grupalidade pode ser esboçada pela gênese e transformação do APG ao longo do tempo.

Num primeiro momento (momento fantasmático) é construída tanto uma identificação entre cada um dos membros para a realização de seus desejos (construção narcísica comum) quanto os mecanismos de defesa e pactos contra os perigos que podem ameaçar 
a grupalidade em questão (pactos denegativos). Como consequiência, são organizados os lugares subjetivos no grupo, são determinadas quais as fantasias permitidas, e configurados os vínculos entre os membros capazes de produzir um efeito comum. Seu efeito é produzir uma realidade imaginária do grupo, uma ilusão isomórfica que unifica a todos, gerando uma identidade das representações, percepções e afetos. As relações anteriores de desejo e proibição podem produzir como efeito o abandono de uma parte das exigências do sujeito singular em favor de um objetivo comum ou de um ideal superior, fato que implica em renúncias e sacrifícios para que o projeto se concretize.

Um segundo momento pode ser identificado como ideológico, onde se produz um achatamento das distâncias entre os lugares destinados a cada sujeito. O grupo vivencia um dilema que perpassa a todos: manter pela força os ideais, a destinação e sentido. Nessa fase, a sistematização do pensamento fornece uma base racional para as contradições e vacilos, por intermédio do enunciado das primeiras regras em comum, a produção normativa e simbólica da realidade psíquica grupal. Elabora-se uma matriz de significações, situando cada membro em um conjunto social e institucional.

Inicia-se, a partir daí, a abertura de espaços no grupo por onde pode surgir novamente o sujeito e a palavra individual: a constituição do pólo homomórfico. Os processos de subjetivação tornam possível a utilização dos espaços e objetos de forma criativa, além de estabelecer uma diferenciação no grupo caracterizada pela construção de um sistema utópico e processos de simbolização mais complexos. O grupo não é mais um prolongamento dos sujeitos, mas o resultado de uma fase personalizante de seus componentes. Esse momento é denominado mitopoético.

Para compreender as transformações temporais do $A P G$, Kaës utiliza o conceito de intermediário; esse funciona nos momentos das descontinuidades, crises ou rupturas do grupo, sendo o mecanismo de passagem entre duas situações conflitantes. Os intermediários são produzidos nas transições que conduzem o grupo, e seus projetos, a uma maior aderência à realidade, impelindo-o às readaptações produtivas. Caracterizamos uma desorganização em um grupo como uma falha na construção de seus intermediários, em níveis psicológico ou sociológico.

Neste trabalho, utilizaremos os conceitos delineados para compreender as ansiedades e iniciativas de professores em uma situação específica de planejamento, execução e avaliação de um projeto coletivo. Veremos que a professora de ciências desempenhou o papel de intermediário, que teve como fruto a elaboração transicional do momento ideológico vivenciado pelo grupo, contribuindo para outro momento grupal marcado pela possessão pessoal e de grande criatividade. Que funções permitem ao grupo gerenciar de 
maneira eficaz as saídas e trocas de professores? Como auxiliar os professores na construção de um sistema utópico que, mesmo em circunstâncias difíceis, consiga ser orientador da ação coletiva?

\section{CONSIDERAÇÕES METODOLÓGICAS}

Este trabalho é uma tentativa de reconstrução interpretativa do processo vivenciado por um grupo de professores do ensino fundamental de uma escola pertencente à Rede Municipal de Ensino de Belo Horizonte, que desde 1995 desenvolvem projetos temáticos coletivos. Estes projetos, já relatados em vários encontros e congressos, têm contribuído de forma significativa na construção de práticas pedagógicas inovadoras. Nossa reconstrução se realizou mediante a triangulação entre $o s$ dados de entrevistas individual e coletiva, realizadas por um dos autores(J.M), os relatos objetivos dos eventos e textos produzidos pela escola, e o modelo teórico de Kaës. A entrevista foi convocada pelo pesquisador, que esboçou anteriormente o seu propósito, para que os participantes soubessem o que esperar das discussões e ficassem à vontade para aderir ou não. Participaram quatro professores, que interagiram com suas idéias e percepções sobre a experiência grupal, e que resultou em descobertas inesperadas, revelando sentimentos, percepções e situações difíceis vivenciadas pelo coletivo.

Os instrumentos utilizados para o registro das entrevistas foram o vídeo (coletiva) e áudio (individual), com a transcrição posterior. $\mathrm{Na}$ análise, focalizamos as formações intermediárias responsáveis pelas articulações e transformações de um momento grupal a outro. Destacar e analisar esses momentos tornou possível uma leitura e interpretação sobre os movimentos consciente e inconsciente que marcaram a evolução do grupo.

\section{ANÁLISE DOS DADOS}

\section{Momento fantasmático: Projeto BH ONTEM E HOJE}

O surgimento de um projeto educativo inovador decorre de necessidades vividas pela instituição, na qual alguns membros conseguem transformá-las em projetos, dos quais se esperam portadores de promessas especiais (ilusão). A proposta de um projeto interdisciplinar (BH Ontem e Hoje) foi elaborada pelos diretores da escola, que aparecem na narrativa como intérpretes privilegiados e garantia de sua realização. Era delineada uma forma de organização do trabalho pedagógico, em ressonância com o Projeto Escola Plural1 (Prefeitura, 1994), para enfrentar as dificuldades vivenciadas no turno da noite, principalmente o absenteísmo dos professores e os altos índices de evasão e repetência dos alunos. Esse momento comporta uma forma de 'realizar corretamente' a tarefa, os caminhos que deverão ser trilhados e os significados e ideais a serem compartilhados, com os quais alguns membros vão dar sentido ao sacrifício e esforço a serem empreendidos no projeto. O diálogo a seguir permitiu visualizar este momento²: 


\begin{abstract}
“Co - Eu me lembro que 1995 é basicamente o ano em que nós resolvemos implantar o Projeto Escola Plural, é (+) trabalhar com projetos interdisciplinares, $n e ́(+)$ e estudamos os caderninhos. A Prefeitura já estava trabalhando com isso na escola primária mas no ginásio não tava ainda. Então eu sei, foi você (J.)1 mesmo que veio conversar comigo sobre, para trabalhar matemática relacionada com outro conteúdo, né? Eu usei um material onde eu relacionava a matemática com a história ...Eu montei o material. Depois eu trabalhei com o material de geografia, quando você (aponta para $Q$.), uma topografia da região de Belo Horizonte, você trouxe um material topográfico de onde?...Em geografia foi isso. Em Ciências a idéia foi explorar graus..."

"J-Essa produção já era coletiva?"

“Q - Na época não existia essa idéia de coletivo não J.”

"Co - Não tinha reunião. Ele me deu este negócio do Parque das Mangabeiras/"

" $\boldsymbol{Q}$ - A intenção de se criar um coletivo eu acho que não estava a vista ainda não, a intenção ainda não. Lembra que você (J.) chamou lá embaixo para uma reunião, tava Eu, o A., a Co. e até você (J.) queria que eu fosse o coordenador do grupo, tá lembrado? Não tinha a intenção do coletivo não, depois que foram surgindo essa (gesto de desdobramento)."

"Co - Você (J.) pediu que a gente trabalhasse com textos, começasse com a linha da Escola Plural, um ano antes que ela fosse implantada no ginásio em geral e em BH. Tentar. Era um experimento. Então assim, cada um ia trazendo alguma coisa e a gente ia montando o material."

"Q - Era muito mais uma adesão, uma iniciativa pessoal mesmo, do que uma (+), uma idéia de grupo mesmo.”
\end{abstract}

Essa adesão relaciona-se ao desejo do diretor, porta-voz das insatisfações geradas no espaço institucional. Porém, o grupo convocado possui marcas que carregam uma predisposição para ouvir e codificar os desejos de formular e sustentar um projeto que tem como característica fornecer-lhes uma resposta (Fernandez, 1998). Devido à ressonância entre diretores, professores e contexto social, podemos supor a disponibilidade desse grupo para investimentos inovadores. Seus membros apontam uma coincidência de idéias em um espaço narcísico ilimitado e partilhado. A fala a seguir transmite a visão que um dos professores tem sobre esse momento:

“ $Q$ - Uma coisa da noite que eu vejo é que a gente trata com pessoas inteligentes né J.? O G., a Cr., a Co., são pessoas inteligentes e que estão articuladas prás coisas. (...) Não adianta também querer pegar de uma hora prá outra (+) surgir um grupo assim (gesto de união) sem as pessoas estarem predispostas a isso. Não sei.”

Subjaz à citação acima o imaginário de uma unidade como um organizador psíquico grupal; predispostos, inteligentes e articulados têm como função garantir os investimentos de cada professor e, simultaneamente, organizar os vínculos intersubjetivos. Tem-se um grupo de professores reunidos em torno de um ideal comum: direcionar a escola para novas formas de aprender e ensinar. Cada membro servirá como guarda desse contrato somos um grupo predisposto à inovação - cujo enunciado será retomado e transmitido nos anos posteriores, às custas de sua própria coerência psíquica e social. Simultaneamente, esse acordo se sustenta na construção de uma 'zona de silêncio': as hostilidades serão dúvidas sobre a validade do projeto e sobre a capacidade do grupo em realizá-lo não serão levantadas, e uma proposta de retorno aos tempos anteriores à (re) fundação serão 
proibidas. Essa a função do pacto denegativo.

Essas predisposições e proibições inauguram a história dessa nova ilusão. Porém, oscilações e contradições são parte desse momento, relacionados à dificuldade de concretizar o projeto. Conforme o diálogo anterior, o projeto é articulado numa perspectiva multidisciplinar e associado à autoridade do fundador. Não houve confronto de pontos de vista que superassem os marcos disciplinares e o trato individualista do projeto pelos professores.

Essa estruturação permitiu localizar o lugar de cada membro bem como engendrou as primeiras fantasias; essas suportam tanto a antecipação de uma experiência que poderia vir a ser satisfatória quanto o medo de 'ser devorado' por ela, isto é, de ser despojado dos elementos que poderiam trazer segurança a cada membro. Esta configuração foi assim racionalizada:

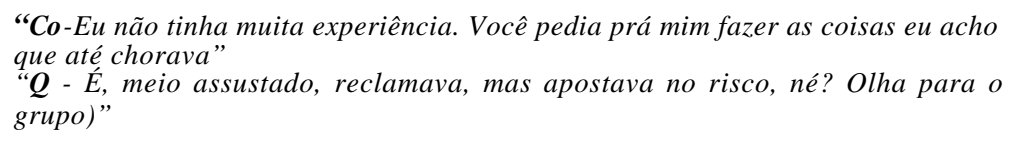

Foram esses modos iniciais de identificação - presos a uma proposta de gestão dos diretores e da Escola Plural, o desejo de estar e o 'juramento' de apostar no risco, a insegurança de não corresponder e o medo de ser excluído - que possibilitaram delimitar papéis e lugares, e instalar os mecanismos de defesa. Tal momento conduz a uma redução das diferenças entre os membros, e essas sensação de homogeneidade não será anulada pelo surgimento de uma relação diferenciadora no grupo. Mesmo tardiamente, o grupo haverá de contar com remanescentes dessa ilusão isomórfica, devido aos mecanismos de defesa que ele proporciona frente a irrupções consideradas perigosas.

O projeto BH Ontem e Hoje teve um caráter experimental, fruto de uma negociação entre o desejável e o que foi efetivamente colocado em cena. Essa transicionalidade adquiriu importância para os membros, pois foi uma resposta adequada às necessidades e insatisfações iniciais. $\mathrm{Na}$ avaliação do grupo, o projeto obteve os seguintes avanços: envolvimento dos coordenadores e diretores; melhoria na relação professor/aluno; integração conteúdo escolar/vivências cotidianas; fortalecimento do coletivo de professores; e a participação de outros professores no projeto. Garantiu-se, em nossa interpretação, um modo original de solucionar parte dos problemas da escola. 
Momento Ideológico Transicional: Projeto Arte de Viver

Consideramos que os diretores, o projeto desenvolvido em 1995 e a utilização do espaço institucional introduzido pela Escola Plural constituíram-se como intermediários na ruptura realizada entre as formas de organização tradicional da escola e o sistema utópico criado pelas novas relações. Esse momento pode ser considerado o 'motor' de uma nova fase que, segundo o relato do grupo, iniciou-se com o Projeto Arte de Viver, em 1996. Nesse momento, o grupo impõe a necessidade da renúncia pulsional e abandono dos ideais pessoais. Duas normas contratuais serão prioritárias para o funcionamento do grupo: a substituição do colega quando este faltasse, e a separação entre professores que trabalhavam com os $1^{\circ}$ e $2^{\circ}$ Graus. Vejamos essa normatização a partir do relato do grupo.

O primeiro passo seria que os professores se dedicassem integralmente ao $1^{\circ} \mathrm{Grau}$, pois caso contrário não se teria a disponibilidade plena de cada um para enfrentar os desafios que surgissem. No diálogo abaixo vemos a primeira regra, quando os entrevistados recordam do retorno do prof. G. à escola após cursar a pós-graduação, e os novos sentidos elaborados em conjunto:

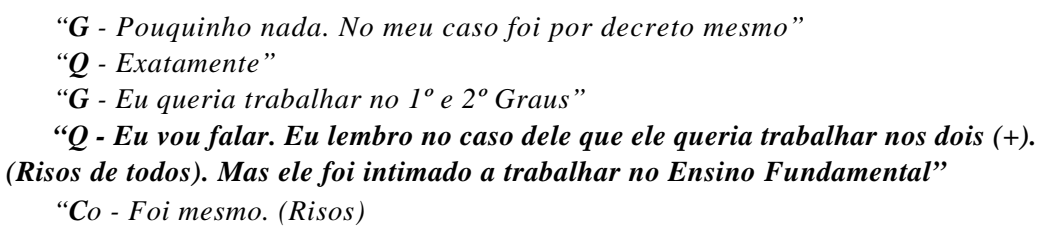

A impressão, conforme o diálogo anterior, é de manter por decreto os lugares e posições que cada um deverá assumir. Outro sacrifício imposto foi que cada professor passou também a ser responsável pela ausência do colega como mecanismo de garantir o funcionamento e a credibilidade do empreendimento proposto. $\mathrm{O}$ trecho abaixo retrata esse desafio:

“ $\boldsymbol{Q}$ - Eu queria voltar J. Eu acho que em 96, com aquele negócio de professor faltando, que a gente resolveu cobrir esse espaço vago, e eu lembro que fui falar numa escola lá no Taquaril (bairro de BH) e eles perguntaram: "Como é que vocês conseguiram isso que o pessoal cobrisse (+) o horário do outro (+), né?" Aî́ na época (+) eu não pensei muito, mas agora, e voltando, acho que foi engajamento mesmo do $(+)$ do grupo em ver as coisas funcionando. Do coletivo mesmol"

"[G-Solidariedade. Compromisso.]" 
" $Q$ - O coletivo de fazer a escola funcionar. Porque na verdade não teria obrigação nenhuma, entre aspas, de tá cobrindo o outro. Mas como ficava o caos em vários aspectos, né? (+) aí a solidariedade, o espírito de coletivo, de (+) de por o negócio prá funcionar, para trabalhar dentro do grupo, e isso foi um ganho que (+) que eu acho dificil de encontrar em outras escolas por aí."

Esta nova forma de identificação permitiu ao grupo assumir os problemas vivenciados como um desafio a ser enfrentado por todos. Cada um deve ser transparente aos olhos dos outros mediante o contrato formatado pelo grupo, gerando umailusão grupal como organizador psíquico do grupo. Estes desafios e o surgimento de novas tarefas $(\mathrm{O}$ Projeto Arte de Viver seria construído em parceria com os alunos) garantiram um investimento de cada um em outra dimensão, provocando relações novas de solidariedade e coordenação de tarefas. A organização curricular reflete esse momento: 


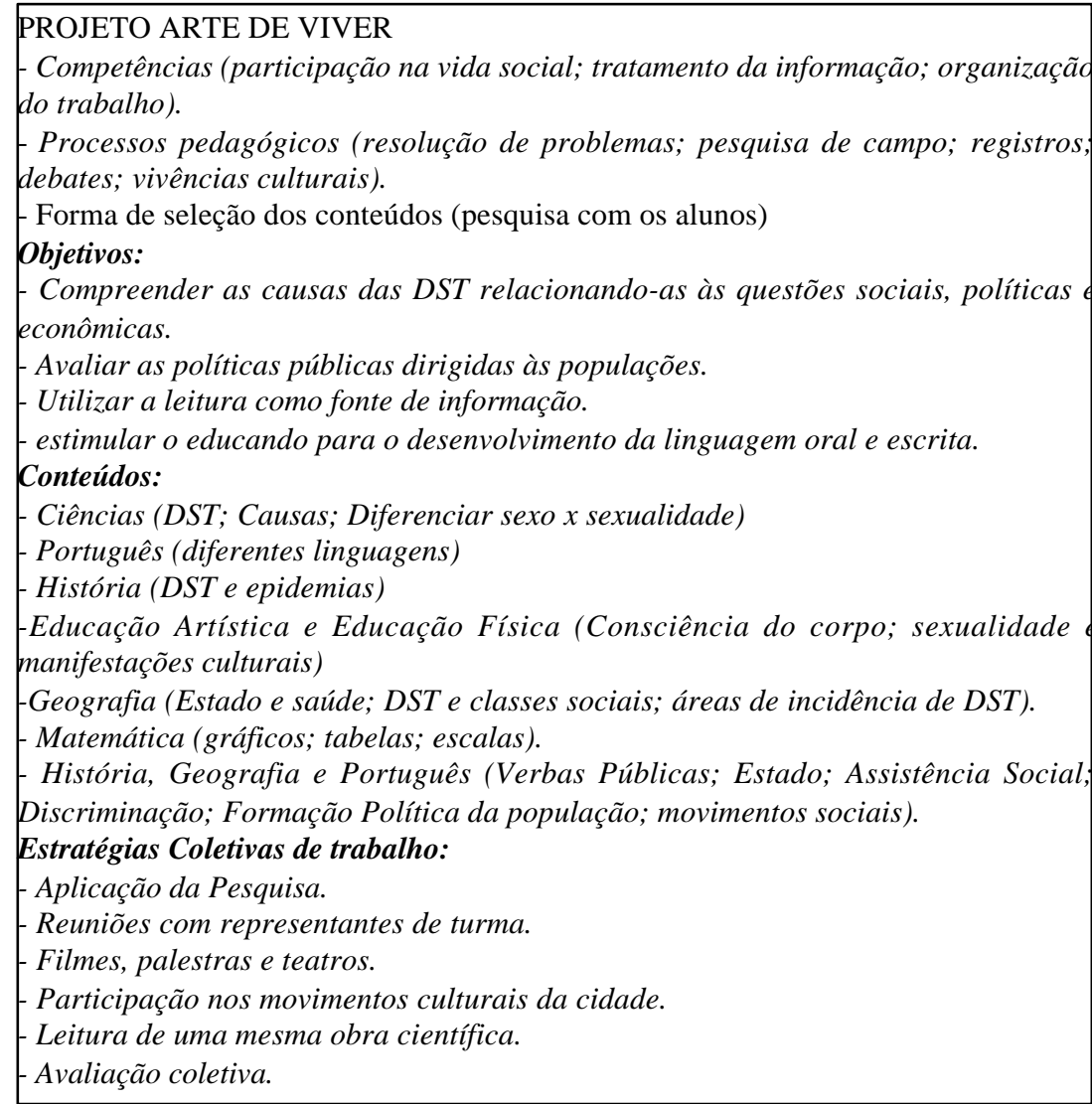

No folder feito pelos coordenadores para o relato do projeto em outras escolas e instâncias da Rede Municipal de Educação foram destacadas as estratégias coletivas de trabalho como o grande avanço conseguido, mas também foi mencionado o não engajamento da disciplina educação física e a saída de uma professora (ciências) do projeto. Encontramos aqui o cerne desse trabalho: que dilemas ocorreram entre o professor e o grupo, motivando a sua exclusão?

Para uma compreensão desse momento, observamos a entrevista concedida pelo coordenador da escola em 1996. Este mencionou o fato de que a professor articulou de forma promissora as relações entre professores, projeto e alunos ao propor a leitura de uma mesma obra científica para todos os alunos. Vejamos parte dessa entrevista:

\footnotetext{
A - Olha, o que marcou mesmo foi a questão da gente estar sempre é:: oxigenando o grupo com novas discussões. A gente sempre tava é:: procurando, por exemplo, é:: uma estratégia nova, até que a gente descobriu aquele negócio de fazer aquela prova coletiva, de todas, aspas, 'de todas as áreas do conhecimento' em torno daquela obra literária (+) a gente conseguiu realmente fazer que o grupo entendesse não existia essa tamanha solidão, né. As pessoas começaram mais a
} 
perguntar para o outro, questionar, trazer idéias, então isso que motivou muito. As pessoas no seu individual começaram a trazer coisas para o coletivo, né, a socializar informações. Então a partir daí começava a montar não uma colcha de retalhos, mas quem queria se apropriava da idéia. Quem não se apropriava da idéia ficava de fora. Que isso foi, eu achei assim (+) um ponto chave. E também tinha assim (+) as motivações que a gente tinha, de estar sempre buscando promover o tipo de trabalho que estava fazendo com o aluno né. Quer dizer, ninguém queria deixar a peteca cair, ninguém queria ver a sua desgraça, a sua caveira, isso é importante né. Então o pessoal se empenhava. Quem não se empenhava também /

J - Como o grupo lidava com essas pessoas que se empenhavam menos?

A - Ta. Eu lembro perfeitamente que havia uma professora, que nunca se empenhou no trabalho, né, e qui de repente ela teve um insight e foi ela que detonou todo o processo. Aquela velha história, né, ninguém esperava nada dela mas ela foi se envolvendo com o grupo, ela só vivia de licença, por motivos pessoais, de repente ela trouxe uma idéia bacana, foi uma idéia legal, que foi a questão de se unir em torno da obra literária, e aí o grupo se motivou, né? Uma pessoa que tava menos envolvida a gente nunca pode delimitar né, esse grau de envolvimento, as vezes essa pessoa tava lá envolvida com outros problemas, mas foi a pessoa que mais contribuiu naquele momento, né. Vendo os outros contribuindo também. Então (+) o único caso que eu lembro foi desta professora. Tava menos envolvida (+) e depois entrou de cabeça no projeto.

A professora, em 1996, apresentava pouca participação nas atividades do projeto (nunca se empenhou no projeto), faltas constantes (42 faltas de março a maio; 156 em 1996) e aparente descompromisso com os conteúdos elaborados (documentos elaborados pelos alunos). Ao ser questionada pela coordenação pedagógica, passou a freqüentar as reuniões semanais de planejamento. Porém, parece que essas reuniões não tinham efeito em sala de aula, diante de críticas dos alunos. Não se trata de destituir o professor de sua autoridade, mas reconhecer - diferentemente de outras escolas - que os alunos participaram da formulação dos conteúdos e estratégias coletivas de trabalho. Mas, em uma das reuniões semanais de planejamento, ela, de forma criativa, sugere a leitura de um texto em conjunto, proposta aceita pelo grupo (foi uma idéia legal, a questão de se unir em torno da obra literária, e aí o grupo se motivou). A estratégia gerou, conforme relato anterior, aquele negócio de fazer aquela prova coletiva, de todas, aspas, 'de todas as áreas do conhecimento' em torno daquela obra literária. Tal estratégia constituiu-se, em nosso entendimento, como intermediário para o grupo.

Por outro lado, documentos do Colegiado Escolar apontam o grande número de faltas do professor ao longo do ano, ressaltando o prejuízo que o mesmo estava causando ao projeto coletivo da escola: Arte de Viver-Jovens Trabalhadores - Sexualidade - DST - Políticas públicas, e a sua atitude de descrédito quanto aos questionamentos dos alunos sobre a pertinência de seus conteúdos e forma de avaliação. Segundo nossa inter- 
pretação, acreditamos residir nessas situações uma falha na manutenção dos vínculos. Primeiro, uma falha com as normas erigidas pelo coletivo, pois seu número de faltas acarretava sacrifícios maiores aos outros professores, responsáveis pela organização escolar na ausência do colega. O contrato normativo estabelecido pelo conjunto implica na Lei como forma de justiça, o elo que mediatiza as relações entre cada membro entre si e com o grupo. Em segundo, mencionar a não pertinência dos conteúdos ao projeto implica um ataque à credibilidade do mesmo, e um possível retorno às práticas individualistas com as quais o grupo procurava romper. Tal fato sugere um ataque ao pacto denegativo construído pelo grupo. A possível permanência da professora implicaria na perda de compromisso ou insuficiência de desejo para com o projeto e o grupo, retornando com os 'conflitos e rivalidade entre os semelhantes', isto é, hostilidades até então recalcadas. Em concordância com Kaës (1997), em 'ser sem destino no desejo do outro e de mais de um outro’. A ilusão grupal funciona aqui em sua versão ideológica, como sequiência última de resolução de conflitos pela abolição do espaço psíquico, indicada pela exclusão da professora. Diante da entrevista e dos documentos da escola percebemos a trajetória oscilante do sujeito e do grupo, e da ambigüidade presente nesse percurso.

Por outro lado, ressalta-se que, mesmo com todos os problemas, o grupo acatou a proposta de um membro que pouco contribuía, demonstrando a capacidade de escuta de seus membros. A exclusão do diferente, nesse momento, sugere a introjeção dos bons objetos e a adequação a uma realidade boa, possibilitando a utilização da ilusão grupal também como intermediário que remete ao início de processos mais complexos. O trabalho de luto impôs a elaboração de novas formas de pensar, reforçando a tomada de consciência da experiência e das relações no grupo como correlato da perda. Trata-se, conforme nos sugere Kaës (1997), de instaurar um vínculo transicional cujas qualidades de continência e segurança não possam ser alteradas pelos processos de subjetivação e do vir-a-ser autônomo.

A partir deste momento o grupo impulsionou-se no sentido de ser mais criativo e independente, local onde os conflitos eram explicitados por cada um, sem receio de perder sua identidade e sem medo de se defrontar com o diferente (Valadares \& Villani, 2001).

\section{CONCLUSÕES}

Ao longo desse trabalho analisamos os caminhos trilhados por professores na construção de projetos interdisciplinares; simultaneamente, apontamos os desafios enfrentados nas relações intersubjetivas ao longo do percurso. Nesse caso específico, o desligamento da professora de ciências no momento em que a construção curricular apresentava grande 
proximidade com os conteúdos da disciplina. Esse tipo de impasse é comumente relatado como um dos grandes desafios na construção de projetos: o professor que, no momento de concretização de um projeto inovador, se apega a queixas e práticas individualistas, provocadoras de um retrocesso em todo o grupo. Decorre daí a validade desse trabalho, isto é, compreender as obrigações, renúncias e benefícios que o sujeito se submete no estar em grupo. Longe de ser apenas uma resistência cognitiva, apontamos aspectos subjetivos na compreensão da situação.

Para tanto, utilizamos o conceito deintermediário que, em nosso entendimento, é suficientemente consistente para a compreensão dos núcleos dramáticos que são encenados nas rupturas e sustentação do trabalho escolar. Mostramos as formações e funções intermediárias por meio das quais se efetuaram as articulações e transformações das formas de organização. Foi necessário, entretanto, supor um aparelho capaz de ligar, de conter, transformar e, principalmente, transmitir as formações e processos psíquicos (contrato narcísico, pacto denegativo, ilusão) que adquiriram um índice de realidade grupal: o aparelho psíquico grupal, em suas modalidades isomórfica e homomórfica.

Tal fato permite-nos compreender o que ocorre em escolas nas quais as práticas dos professores são nomeadas individuais e fragmentadas. Em nossa interpretação, as normas institucionais marcam fortemente as atividades docentes, determinando os lugares e as posições psíquicas e simbólicas que cada professor ocupa, e quais relações permitidas. Essa organização mantém um 'bolsão de silêncio' - as insatisfações deverão ser reprimidas (aqui é um ambiente familiar) -, apoiado em uma visão de escola protetora de seus sujeitos ou, então, a agressividade é dirigida para elementos externos, tais como a Instituição, os alunos e famílias. Cada professor que chega, portador de ideais oriundos de experiências prévias, deverá ser submetido aos benefícios e promessas dessa ilusão isomórfica e não simbolizará ataques ao 'bolsão' (pactos denegativos). Se tal acontece, podem ocorrer duas situações: primeiramente, pode-se criar um espaço de nãorepresentação, isto é, o professor e sua prática não serão reconhecidos na escola, e uma situação intolerável decorre desse dilema. Em segundo, sua prática ativa o desejo de mudança e quebra-se o contrato narcísico. Temos um vazio gerado nessa mudança, e uma idéia inovadora perpassa os professores, isto é, a inauguração do contrato narcísico em uma nova linhagem, simultaneamente à instauração de um pacto denegativo, recalcador das agressividades que podem surgir dessa transformação. Anterior à uma nova idéia ou projeto para a escola, alguém pode assumir um lugar de ídolo ou fetiche, sendo porta-voz dessa mudança. Por isso, as eleições diretas para diretor, fruto do espaço institucional, quanto um membro do grupo ou uma idéia portadora de uma promessa, resultante de um 
interjogo interno, podem se constituir como intermediários.

A maior dificuldade está ligada ao nascimento do grupo em uma nova isomorfia. O caminho apontado por esse grupo, em nossa visão, permite compreender aspectos dos riscos envolvidos, e auxiliar outros grupos de professores na vivência dos dilemas e conflitos. O fundador do grupo desempenha um importante papel no momento originário. Se capturado pelo discurso da inovação, ele transforma as insatisfações, expectativas e medos de cada participante em formas de co-participação, de maneira que as primeiras identificações entre os membros são inseridas em uma vivência de positiva potencialidade. São estas fantasias imaginárias que permitirão, em um momento posterior da evolução do grupo, a possibilidade de uma reconstrução subjetiva através da criação de um espaço potencial para o debate de idéias, refletindo uma experiência de convivência com a diferença (homomorfismo).

Por outro lado, encontramos a formulação do pacto denegativo, isto é, as zonas de silêncio que não poderão ser abordadas, pois necessárias à manutenção do vínculo. Relaciona-se, nesse trabalho, com a impossibilidade de trazer dúvidas e incertezas quanto ao projeto inovador a ser desenvolvido, bem como uma volta a práticas anteriores à fundação do projeto. Porém, uma resposta rápida parece também necessária: a concretização do projeto, mesmo que experimental, pois é a garantia de uma articulação entre escola, professores e alunos. Essa fase fantasmática do $A P G$, na qual ocorre uma aproximação entre os membros e as promessas geradas é, portanto, essencial.

Consolidado os intermediários acima, o grupo inaugura uma outra fase, na qual as fantasias e contratos são simbolizados e busca-se a estabilização dessa nova ilusão isomórfica. Aqui encontramos a ilusão grupal, que funciona em versões ideológica - os conflitos também são resolvidos à força - ou transicional - abrindo caminhos para a fase mitopoética . No contexto desse trabalho, percebemos as duas versões; a ideológica, pela exclusão da professora; como intermediário, pela abertura de novos caminhos e formas de trabalho no grupo. Corre-se, aqui, um risco. Nessa fase, o grupo e seus projetos alcançam grande êxito devido à estabilidade adquirida, e, por isso seus membros, em função dos benefícios que retiram do impacto das atividades desenvolvidas, mantêm uma forte tendência a manterem essa fase. Porém, a ilusão grupal pode significar a delimitação do espaço do grupo, que se isola do contexto institucional.

As conclusões acima permitem ampliar o trabalho de análise sobre as relações entre sujeitos, grupos e instituição. Existem exigências que são impostas pelo grupo/instituição ao sujeito (proibições principais, ser portador do contrato narcísico e do investir na 
formação imaginária do conjunto, renúncias e sacrifícios pulsionais, obrigações simbólicas e de conformação à norma), e que convergem (ou não) para as condições de submetimento ao grupo como exigências do próprio sujeito (proteção, suporte narcísico, enunciação de proibições estruturantes, exigência de predisposições significantes). Assim, dessas relações cruzadas, o sujeito procura e encontra no grupo uma pertinência identitária, que o fazem reconhecer-se e ser reconhecido como membro do coletivo. A vida em grupo implica os deveres que cada membro terá de preencher em troca do investimento, como objeto, do coletivo. Cada membro se ancora no grupo e nos ideais legados, e, a partir daí, elabora sua própria identidade: um sujeito do e no grupo.

\section{BIBLIOGRAFIA}

FERNÁNDEZ, Lidia M (1998): Crise e dramática da mudança: avanços de pesquisa sobre projetos de inovação educativa. In: BUTELMAN, Ida (org): Pensando as instituições: teorias e práticas em educação. Tradução Jussara Haubert Rodrigues. - Porto Alegre: ArtMed.

KAËS, René (1991): Realidade Psíquica e Sofrimento nas Instituições. In: KAËS, René et al.: A Instituição e as instituições: estudos psicanalíticos. Trad. Joaquim Pereira Neto. - São Paulo: Casa do Psicólogo.

KAËS, René (1997): O grupo e o sujeito do grupo: elementos para uma teoria psicanalítica do grupo. Tradução José de Souza e Mello Werneck - SP: Casa do Psicológo

PRefeitura De Belo horizonte (1994): Escola Plural: Proposta Políticopedagógica. Secretaria Municipal de Educação: Belo Horizonte.

VALADARES, Juarez M. \& VILLANI, Alberto (2001): As formas e a construção da (inter)subjetividade em um grupo de professores: análise de uma prática e seus discursos. Atas do III ENPEC. Atibaia.

VALADARES, Juarez M. \& VILLANI, Alberto (2002): Continuidade e ruptura no trabalho coletivo de professores. Atas do VIII EPEF. São Paulo: Águas de Lindóia.

VALADARES, Juarez M. (2002): As formas e a construção da subjetividade em um grupo de professores: análise de uma prática e seus discursos. Dissertação de Mestrado - Instituto de Física - Universidade de São Paulo.

VALADARES, Juarez M. \& Villani, Alberto (2003): Um referencial psicanalítico para os grupos de aprendizagem em Ciências. Atas do IV ENPEC. São Paulo: Bauru. 